IOS Press

\title{
Foreword
}

\section{Foreword to Advances in Communication and Swallowing Volume 24, Issue 2}

We are delighted to welcome you to Issue 2 of Volume 24, of Advances in Communication and Swallowing (ACS) - our first issue of 2022!

Building on the success of the launch of ACS last year, we continue to bring you papers of high quality and diverse topics within the areas of speech, voice, language, communication, swallowing and related professional issues.

In this issue, our papers fall into three main topic areas: (i) the speech-fluency disorder of cluttering; (ii) considerations associated with communication disability following stroke, and (iii) professional concerns, including staff retention and student education.

This issue also has a truly international complexion, as contributors hail from no less than three continents, including North America, Australia, and Europe. The international dimension to this issue is testament to the scholarly motivation and interest among our multidisciplinary community to share their research with colleagues beyond geographical boundaries. This global reach is something ACS aims to promote and nurture, as we live in this ever-changing and ever-challenging world of the 21 st century.

We would like to thank all involved in bringing this second issue of Volume 24 to fruition, especially our contributors and reviewers. We continue to encourage our community to consider publishing in future issues of ACS, so that we may continue to bring you high quality reviews, cutting edge research, and topical contributions of relevance to processes and practices in our respective clinical fields.

Julie Regan Irene P. Walsh

Editors in Chief January 2022 